\title{
Existential, Relatedness, Growth (ERG) needs' dimensions of medical students for rural posting - An analytical study
}

\author{
J.Shanmugapriya \\ Ph. D Research scholar, IIHMR University, Jaipur, Rajasthan ,India
}

Article History: Received: 10 November 2020; Revised 12 January 2021 Accepted: 27 January 2021; Published online: 5 April 2021

\begin{abstract}
The retention of rural doctors in India is a very big challenge. Despite the mandatory rural postings, year by year rural health statistics indicate an abysmal picture of rural doctors' vacancies and their shortfalls in many states. Various studies stipulate that rural doctors are quitting rural postings. A reliable instrument to identify the motivational needs of doctors towards their rural postings, suitable to the Indian context, which is vital for both policymakers and doctors alike. So, this study aims to acquire the reliability of the Existential, relatedness, and Growth needs of Doctors' questionnaire and to obtain the dimensions of needs as an initial attempt. An ERG motivational need questionnaire was developed to explain the needs of medical graduates and rurally placed physicians in Indian context. A literature search and pilot study with 64 medical students conducted and relevant items were extracted. This study was conducted in Jaipur, Chennai, and Pondicherry. The reduction of items was done through principal component analysis in SPSS. Cronbach Alpha coefficient is considered to measure for internal consistency reliability of the instrument. The instrument is developed with three constructs namely Existential needs (EN), Relatedness Needs (RN), and Growth Needs (GN) with a 5-point Likert scale. The exploratory factor analysis after three rotations converged to 9 factors with 74.103 total variance and 0.606 Kaiser-Meyer- Olkin index indicating sampling adequacy. The initial scale items (with 58 Items) were reduced to 9 factors with 28 items in the final questionnaire. Overall scale is with Cronbach alpha value of 0.851 for these items. The result obtained has proven that the extracted 9 factors have good reliability to obtain the dimensions of Existential, relatedness, and growth needs. The study results have implications in addressing the problem of Rural doctors' shortage.
\end{abstract}

Keywords: Rural doctors, ERG needs, Factor Analysis, Reliability

\section{Background}

"The designed medical education does not adequately prepare the students for rural service, and the medical students expressed that they are reluctant to work in rural areas due to the insufficiency of physical amenities, communication facilities, and professional advancements". (Sapkota \& Amatya, 2015). "Practicing medicine in rural areas were found to be poor, and their intent to migrate after completing medical training was found to be very high, It is creating a huge potential for brain drain".(Deressa \& Azazh, 2012). "Urban background students have more negative descriptors about rural areas" (Ray, Young, \& Lindsay, 2015), "Students expressed concerns about being 'forced' to work in non-metropolitan hospitals and received little warning of the placement, causing anxiety and concern" (Brodribb, Zadoroznyj, \& Martin, 2016). "Medical students said they would never work in a rural community with a population of less than 10,000 and almost they want to work overseas within five years."(Schofield, Fletcher, Fuller, Birden, \& Page, 2009). "The current rural health services to be unsatisfactory. Fewer students were willing to serve in rural areas. The majority were only willing to work in rural areas for less than a year in Chhatisgarh - India" (Jain, Gupta, Gupta, \& Roy, 2016) "Many of them from the rural stream had no long-term plans to establish rural practices".(Tolhurst et al., 2008). "Indian Allopathic graduates aimed to specialize and preferred private-sector jobs." (Ramani, Rao, Ryan, Vujicic, \& Berman, 2013). All this literature draws attention to the severe aversion of medical students towards rural practice. "Retention and recruitment strategies may not affect if they are designed without considering the needs of health workers"(Lanktree, Cohen, Larocque, \& Omaswa, 2014). "Policy makers can provide need-specific motivational packages for rural placed doctors in order to reduce the professionals shortage." (Shiratori et al., 2016). Every human being has expectations based on needs, which if fulfilled results in motivation and the optimal performance. When on the part of doctors, the work performance directly relates to the patients, if they are demotivated, not only their skills are underutilized but also the Government is not able to serve the needy. For this purpose, the literature search was conducted on rural doctors' shortage and preferences of Medical students towards rural postings. It helps in finding various factors reasoned by many authors. In this backdrop, this study targeted to pilot, more specific to the context and reliable instrument to assess the level of motivation through a focus on existential, relatedness, and growth needs for Indian Doctors in Government services and or rural practice after finishing their qualification. 


\section{Rationale For The Study}

Though developing consensus to identify the needs of medical graduates and rurally placed doctors is subjective, there is a necessity to acquire the tool that can measure their existential, relatedness and growth needs suitable for the Indian context. The current study is an initiative to enhance the instrument which includes the needs of living conditions, spousal factors and children education which were undermined by most of the studies. Hence, it adds a great value to the previous tools used in the Indian context.

This study tries to match Alderfer's ERG theory of need factors in the context of rural doctors. The adaptation of a new instrument intends to measure the level of motivation which will provide useful and practical suggestions for policymakers. For this purpose, initially, the existing literature related to rural doctor's shortage and reasoned factors were identified as a guide, to develop a new questionnaire based on ERG needs. Next, the extraction of needs dimensions and the reliability of the developed questionnaire were appraised. The research questions adopted in this study are:

1. To acquire the reliability of Existential, Relatedness, and Growth needs of Doctors questionnaire.

2. To obtain the Dimensions of Existential Relatedness and Growth needs.

\section{Erg Motivational Needs (Alderfer's Erg Model):}

The acronym ERG stands for three groups of fundamental needs, they are Existential, Relatedness and Growth needs. These needs are line up with the Malow's hierarchy of needs. But Alderfer developed the needs into a theory of his own (ERG theory). However, it differs from Maslow's theory in three ways: "A lower-level need does not have to be gratified (i.e., a person may satisfy a need at hand, whether or not a previous need has been satisfied); If a relatively more significant need is not gratified, the desire to gratify a lesser need will be increased (i.e., the frustration in meeting high-order needs might lead a person to regress to a more concrete need category), the order of the needs to differ for different people (e.g., it accounts for the "starving artist" who may place growth needs above existence ones)" (Alderfer, 1969).

a) Existential needs: "This group of needs is concerned with providing the basic requirements for material existence, such as physiological and safety needs. In a work context, this need is satisfied by money earned in a job for survival and other existential requirements." (Alderfer, 1969).

b) Relatedness needs: "This group of needs focuses on the desire to establish and maintain interpersonal relationships with family, friends, co-workers, and employers. This need includes the need to interact with other people, receive public recognition, and feel secure around people." (Alderfer, 1969)

c) Growth needs: "These needs are about the fulfilment of desires to be creative, productive, and to complete meaningful tasks to build and enhance a person's self-esteem through personal achievement." (Alderfer, 1969)

\section{Materials And Methods}

\section{(a) Validated scales considered for development of questionnaire:}

(i) ERG Theory-based Instruments: Two papers were elicited that used instrument based on ERG needs, and items with Alderfer's theory. One is based on a three-fold conceptualization of human needs: "Existence needsincluding the need for basic material necessities, an individual's physiological and physical safety needs; Relatedness needs- including the aspiration individuals have for maintaining significant interpersonal relationships (be it with family, peers or superiors), getting public fame and recognition; Growth needs- including the need for self-development, personal growth, and advancement." (Alderfer, 1969).This paper was used in designing the conceptual framework for this study. The other paper included nine work characteristics based on ERG needs (Steidle \& Gockel, 2013). This paper was used to collate the useful items relevant to this study.

(ii) Motivation instruments: As the study is focussed on the measurement of motivation, the tools on motivation were also given due consideration. To give focus on the Indian context, validated motivation tool with 18 items was taken (Purohit, Maneskar, \& Saxena, 2016) which was in the line of sight to the flow of this work. Another seven items considered from the validated scale based on Maslow's need theory and Herzberg motivation theory were also included for item generation. (Paleologou, Kontodimopoulos, Stamouli, Aletras, \& Niakas, 2006)

(iii) Job Satisfaction instruments: Satisfaction related factors were identified from three of the instruments, which were already validated. Minnesota satisfaction questionnaire- short form (with 20 items)(Martins \& Proenca, 2012), was helpful as most of the items pertinent to the ERG needs. Another study explored for the items was Misener Nurse Practitioner Job Satisfaction Scale (MNPJSS) (Misener, T. R., \& Cox, D. L. (2001)., Job 
satisfaction scale with 16 items (Deriba, Sinke, Ereso, \& Badacho, 2017a) was also considered for selection of suitable variables.

(iv). Other sources: Along with the basic scales, some of the factors itemized to the study were taken from various quantitative and qualitative works, such as retention practice scale with 17 items, (Habeck, Hunt, Rachel, Kregel, \& Chan, 2010)Local Environment Limiting factors based on living conditions and social dimension (Belaid, Dagenais, Moha, \& Ridde, 2017), Family and Children education factors, (McGrail, Russell, \& O'Sullivan, 2017) Spousal influence factors, (Myroniuk, Adamiak, Bajaj, \& Myhre, 2016) Growth needs and rural upbringing factors specifying Solidarity and Reciprocity principle, Equity Lenz and Professional development (Huicho et al., 2015). After collection of as many items from the above-said instruments and qualitative studies, the item generation started following the Existence, relatedness, and growth needs. The overlapping items from different studies were found and removed, and then the classification was made.

(b) Survey Instrument : From the above sources, 58 self-reported items were selected for this study. The questionnaire used in the current study consisted of 19 items for the measurement of existential needs, 19 items for the measurement of relatedness needs, and 20 items for the measurement of Growth needs. (Table 1). A fivepoint Likert scale ( $1=$ Not at all Important, $2=$ Not much important, $3=$ Desirable (Pleasing and Nice if we have), 4 = Essential (Important, should be there) 5 extremely vital (must be there, non-negotiable) was used for each item.

The content validity of this 58-item initial questionnaire tested with the HR and Research expert. As per the advice of the expert, face validity of questionnaire diagnosed with Focussed Group interview among the eight people, it is the crew of rural placed doctors, Rural internship students, human resource authorities in health administration team, District public health officials. The critiques and suggestions were accepted, and modifications were done accordingly.

(c) Research Context and participants: A survey was created and administered using the Google forms, but the response rate was low, so the hard copy questionnaires were also distributed, and coding was done manually for the same. The participants were medical Students from both Government and Private medical colleges of Jaipur, Chennai, and Pondicherry as they are the future workforce. Their education status varied from presently enrolled in academic education to Super speciality. There were 64 students who participated in this study, 45 of them were from academic education student cohort, 12 from the internship period, 3 from P.G. Diploma and 4 from the super speciality. There was a participation of 37 male students and 27 female students. The 25 students were below 20 years of age, 35 students in 21-30 years of age and 4 of them were above 30 . There were 41 urban and 23 rural origin students. Among 64 students, 53 were noted that their choice of location is within the native country, but only 20 of them were willing to work in rural areas. The respondents' comments and suggestions were taken into consideration for further analysis.

\section{Results and analysis:}

Table1: Reliability

\begin{tabular}{|c|c|}
\hline $\begin{array}{c}\text { Cronbach's } \\
\text { Alpha }\end{array}$ & N of Items \\
\hline .936 & 58 \\
\hline
\end{tabular}

The reliability for 58 items indicates that 0.936 which is good reliability to continue further analysis.

Table 2: Descriptive statistics of each element of the ERG needs of Doctors' instrument

\begin{tabular}{|l|l|c|c|c|c|}
\hline & $\mathrm{N}$ & $\mathrm{m}^{\text {Minimu }}$ & Maximu & Mean & $\begin{array}{c}\text { Std. } \\
\text { Deviation }\end{array}$ \\
\hline Existential needs & 64 & 2.84 & 4.95 & $\mathbf{3 . 9 9 2 6}$ & .45187 \\
Relatedness needs & 64 & 2.89 & 5.00 & $\mathbf{4 . 0 3 4 5}$ & .43027 \\
Growth needs & 64 & 3.00 & 5.00 & $\mathbf{3 . 9 5 3 9}$ & .36224 \\
Valid N (listwise) & 64 & & & & \\
\hline
\end{tabular}

It revealed that participating students had a high-level preference towards all these needs. All mean values indicate a score nearing 4, which meant Essential (Important, should be there) as per the Likert scale designed for this study. 


\section{Exploratory Factor Analysis (EFA) for Validity}

To remove the inappropriate items, to achieve the dimensionality of constructs and to increase the reliability of the scale Exploratory factor analysis(Netemeyer, Bearden, \& Sharma, 2003) done for the study.

Table 3: KMO and Bartlett's Test

\begin{tabular}{|ll|l|}
\hline Kaiser-Meyer-Olkin Measure of Sampling Adequacy. & .606 \\
& Approx. Chi-Square & 946.830 \\
Bartlett's Test of Sphericity & df & 406 \\
& Sig. & .000 \\
\hline
\end{tabular}

The KMO measures the sampling adequacy, which should be close to or above 0.5 for a satisfactory analysis to proceed. Kaiser (1974) recommended (0.5 value for KMO) as a minimum. The KMO verified the sampling adequacy for this analysis KMO $=0.606$ (mediocre) according to Field (2009) Bartlett's test of sphericity chisquare is $946, p<0.000$ indicated that correlations between items were sufficiently large for further analysis.

Scree plot and variance explained : In this study, the three factors (i.e., Existential needs, Relatedness needs and Growth needs) were used to determine the pattern of the structure in the 58-item instrument for ERG needs of Doctors' to create a scree plot (Thompson, 2004). Initially, 18 factors were divided, but after 3 rotations it reduced to 9 factors.

The final 9-factor structure in this study was composed of 28 items obtained after deleting the cross-loaded items in more than one factor and deleting the items not shown in any of the factors, as shown in the table. The first factor retained with 5 items, $2^{\text {nd }}$ with 5 items, $3^{\text {rd }}$ with 5 items, $4^{\text {th }}$ with 3 items, 5 th, $6^{\text {th }}, 7^{\text {th }}, 8^{\text {th }}$ and $9^{\text {th }}$ factors each retained with 2 items.

The 28 -item structure was found to explain $74.10 \%$ of variance in the pattern of relationships among the items shown in table. The percentages explained by each factor were $25.196 \%$ (factor 1), $9.864 \%$ (factor 2), $7.974 \%$ (factor 3 ), $7.431 \%$ (factor 4), $5.745 \%$ (factor 5), $5.207 \%$ (factor 6 ), $4.456 \%$ ( factor 7 ), $4.293 \%$ (factor 8 ) and $3.937 \%$ (factor 9) respectively.

Fig.1: Scree plot and percentage of variance explained 


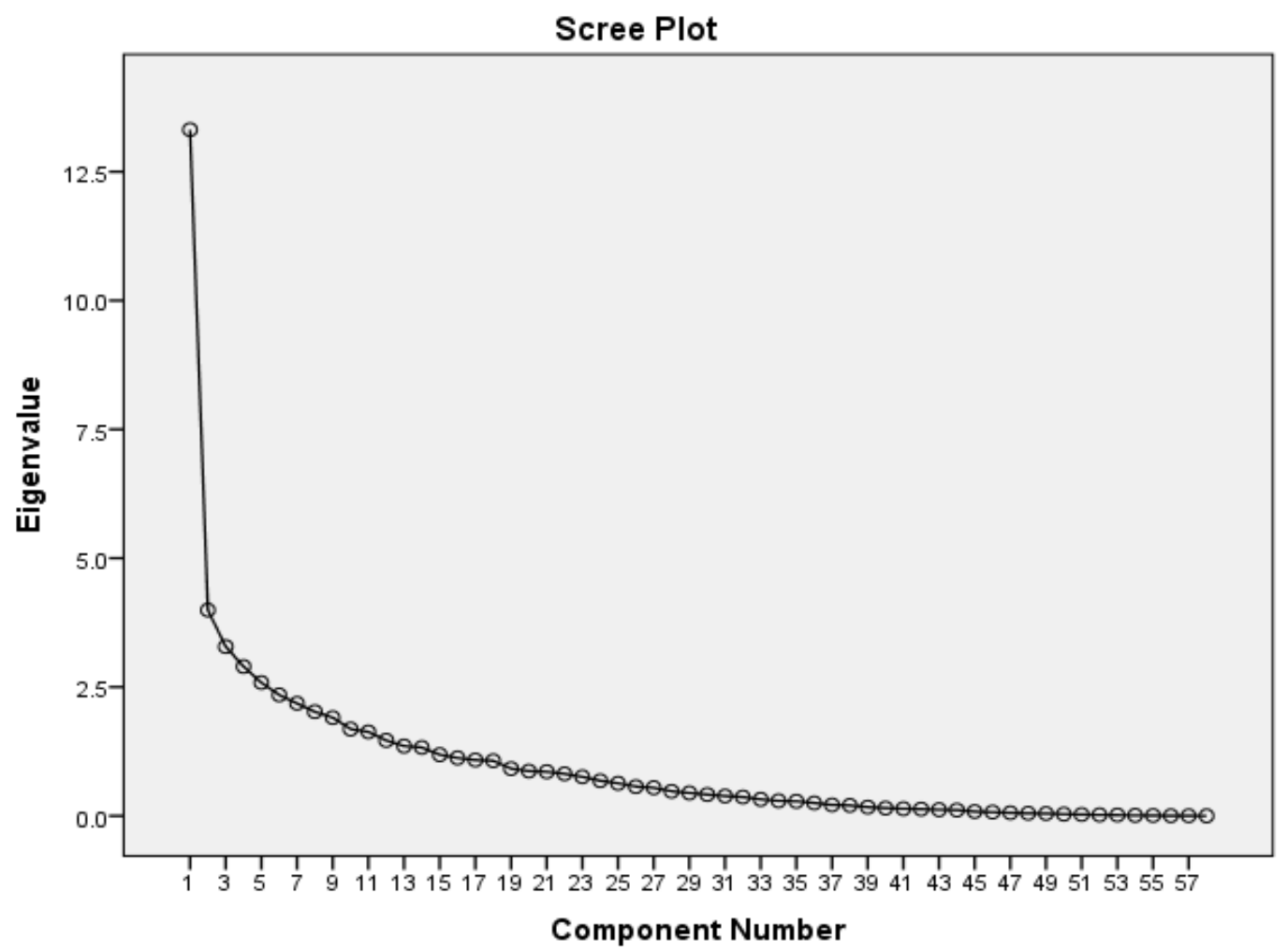

\begin{tabular}{|c|c|c|c|c|c|c|c|c|c|}
\hline \multicolumn{10}{|c|}{ Total Variance Explained } \\
\hline \multirow[t]{2}{*}{ Component } & \multicolumn{3}{|c|}{ Initial Eigenvalues } & \multicolumn{3}{|c|}{$\begin{array}{l}\text { Extraction Sums of Squared } \\
\text { Loadings }\end{array}$} & \multicolumn{3}{|c|}{$\begin{array}{l}\text { Rotation Sums of Squared } \\
\text { Loadings }\end{array}$} \\
\hline & Total & \begin{tabular}{|lr}
$\%$ & of \\
variance
\end{tabular} & $\begin{array}{l}\text { Cumulative } \\
\%\end{array}$ & Total & $\begin{array}{ll}\% & \text { of } \\
\text { variance }\end{array}$ & \begin{tabular}{|l|} 
Cumulative \\
$\%$
\end{tabular} & Total & $\begin{array}{l}\% \text { of } \\
\text { variance }\end{array}$ & $\begin{array}{l}\text { Cumulative } \\
\%\end{array}$ \\
\hline 1 & 7.055 & 25.196 & 25.196 & 7.055 & 25.196 & 25.196 & 3.497 & 12.490 & 12.490 \\
\hline 2 & 2.762 & 9.864 & 35.060 & 2.762 & 9.864 & 35.060 & 3.119 & 11.140 & 23.630 \\
\hline 3 & 2.233 & 7.974 & 43.034 & 2.233 & 7.974 & 43.034 & 2.731 & 9.752 & 33.382 \\
\hline 4 & 2.081 & 7.431 & 50.465 & 2.081 & 7.431 & 50.465 & 2.112 & 7.542 & 40.924 \\
\hline 5 & 1.609 & 5.745 & 56.209 & 1.609 & 5.745 & 56.209 & 1.986 & 7.092 & 48.016 \\
\hline 6 & 1.458 & 5.207 & 61.417 & 1.458 & 5.207 & 61.417 & 1.940 & 6.930 & 54.946 \\
\hline 7 & 1.248 & 4.456 & 65.873 & 1.248 & 4.456 & 65.873 & 1.923 & 6.868 & 61.814 \\
\hline 8 & 1.202 & 4.293 & 70.166 & 1.202 & 4.293 & 70.166 & 1.727 & 6.166 & 67.980 \\
\hline 9 & 1.102 & 3.937 & 74.103 & 1.102 & 3.937 & 74.103 & 1.714 & 6.122 & 74.103 \\
\hline
\end{tabular}

Table4: Reliability statistics for ERG dimensions

\begin{tabular}{|c|c|}
\hline $\begin{array}{c}\text { Cronbach's } \\
\text { Alpha }\end{array}$ & N of Items \\
\hline .851 & 28 \\
\hline
\end{tabular}

The reliability of overall 28 items included for this ascertained scale is 0.851 , that is reliable(Taber, 2018). The Cronbach value indicates in this study that the first 4 factors have high reliability (>0.7) and the next 4 factors have moderate reliability $(0.5-0.7)$, and the final factor is somewhat less reliable, but it is sufficient $(0.45-$ 0.96)(Taber, 2018)to add the items in the developed scale, and, no items were removed after the reliability test in this scale. So, with the 28 items, the ERG needs Dimensions identified by this study.

Table 5: Labelled factors and reliability 


\begin{tabular}{|c|c|c|c|}
\hline $\begin{array}{l}\text { Labelled } \\
\text { Factors }\end{array}$ & $\begin{array}{l}\text { Cronbach } \\
\text { Alpha } \\
\text { value }\end{array}$ & $\begin{array}{l}\text { No.of } \\
\text { Items }\end{array}$ & Items \\
\hline \multirow{5}{*}{$\begin{array}{l}\text { Conducive } \\
\text { external and } \\
\text { internal } \\
\text { Environment }\end{array}$} & \multirow{5}{*}{0.828} & \multirow[t]{5}{*}{5} & Information and Communication Technology facilities \\
\hline & & & Free from the challenge of privacy \\
\hline & & & School for children \\
\hline & & & Effective teamwork \\
\hline & & & Opportunities for advancements in career \\
\hline \multirow{5}{*}{$\begin{array}{l}\text { Working } \\
\text { conditions }\end{array}$} & \multirow[t]{5}{*}{0.825} & \multirow[t]{5}{*}{5} & Physical safety \\
\hline & & & Physical working conditions with water, electricity and transport \\
\hline & & & Satisfactory physical surroundings \\
\hline & & & Salary and fringe benefits \\
\hline & & & Pleasant working conditions \\
\hline \multirow{5}{*}{$\begin{array}{l}\text { Supportive Fear } \\
\text { free ambience }\end{array}$} & \multirow[t]{5}{*}{0.737} & \multirow[t]{5}{*}{5} & Free from local insecurity \\
\hline & & & Supervisors support \\
\hline & & & Safe and attractive working environment \\
\hline & & & Free from social isolation \\
\hline & & & Social contacts with colleagues after work \\
\hline \multirow[t]{3}{*}{ Family needs } & \multirow[t]{3}{*}{0.701} & \multirow[t]{3}{*}{3} & Spousal fulfilments \\
\hline & & & Undisrupted family life \\
\hline & & & Family welfare \\
\hline \multirow[t]{2}{*}{ Esteem in Job } & \multirow[t]{2}{*}{0.688} & \multirow[t]{2}{*}{2} & Level of autonomy in the job \\
\hline & & & Staff respect each other. \\
\hline \multirow{2}{*}{$\begin{array}{l}\text { Earning } \\
\text { augmentation } \\
\text { opportunities }\end{array}$} & \multirow[t]{2}{*}{0.589} & \multirow[t]{2}{*}{2} & $\begin{array}{l}\text { Opportunities to receive compensation for services performed outside } \\
\text { of your normal duties }\end{array}$ \\
\hline & & & Flexibility in practice protocols \\
\hline \multirow[t]{2}{*}{ Job outlooks } & \multirow[t]{2}{*}{0.672} & \multirow[t]{2}{*}{2} & Promotion opportunities \\
\hline & & & Job security \\
\hline \multirow[t]{2}{*}{ Learning } & \multirow[t]{2}{*}{0.557} & \multirow[t]{2}{*}{2} & Support for continuing my education \\
\hline & & & Initial training for my learning \\
\hline \multirow[t]{2}{*}{ Job value } & \multirow[t]{2}{*}{0.468} & \multirow[t]{2}{*}{2} & Sense of value for what I do \\
\hline & & & Co-workers get along with each other. \\
\hline
\end{tabular}

\section{Discussion:}

Of the final 28 items included in the tool, 14 were existential needs, namely: information and communication technology facilities, the school for children, free from challenge of privacy, physical safety, physical working conditions with water and electricity, satisfactory physical surroundings, salary and fringe benefits, pleasant working conditions, safe and attractive work environment, free from social isolation, and job security. The 6 relatedness needs were: effective teamwork, supervisor's support, social contacts with colleagues after work, spousal fulfilments and staff respect each other. Furthermore, the 8 growth needs, were: opportunities for advancements in career, level of autonomy in the job, opportunities receive compensation for services performed outside of normal duties, flexibility for practice protocols, promotion opportunities, support for continuing education, initial training for learning, and sense of value for what I do.

Although developing consensus to assess the needs of medical students and doctors in rural placements is subjective, there is an urgent need to develop the tools that can measure their existential, relatedness and growth needs suitable for the Indian context. Several scales and tools are used in the management studies to ascertain the motivation, satisfaction, and retention with respect to rural doctors, but the present study is the first effort to find the dimensions and to develop the instrument, which includes the needs of living conditions, spousal factors and children education which were undermined by most of the studies, so it adds a great value to the previous tools used in the Indian context.

The study findings indicate that 14 out of 28 factors are existential needs, Although Doctors are in Professional category, they are not only aspiring for their highest order needs but also concerned for basic needs in their workplace. Hence one of the recommendations, as supported by research elsewhere, is that the Government should concentrate on living conditions. However, the study findings also indicate that relatedness and growth needs cannot be ignored as 14 out of 28 items included for further work belonged to these needs. The 8 growth 
needs indicate the predisposition of medical students towards advancements, autonomy in the job, promotion, education, and training opportunities.

This study has been using the previous literature and comprehensive reviews with regards to Alderfer's ERG motivation theory as a guide to developing a new instrument to measure the level of motivation. At this exploration stage, the reliability of the questionnaire was proven to derive the dimensions of ERG needs of rural doctors. As an outcome from Factor analysis, nine factors of the instrument of Existential, Relatedness, and Growth needs to clarify 74.103 per cent of the variance among the items. Eight factors produce high and moderate reliability, and item having sufficient reliability and 28 items remained. As a result, 9 factors of ERG need dimensions have been established through this study. Moreover, the items not contributing to exploring the dimension of ERG needs were dropped.

\section{Conclusion:}

This study is an effort to exploring the dimensions of Existential, relatedness, and Growth needs of medical students and doctors to join rural places. Of 28 needs, 14 were existential needs indicate that medical students have more expectations on basic needs in rural areas. Furthermore, 6 of relatedness and 8 growth needs also play an ideal role in deciding the rural placements. The results of the study have great implication for designing the HRM Strategies and for addressing the problem of rural doctors' shortage.

\section{References}

Alderfer, C. P. (1969). An empirical test of a new theory of human needs. Organizational Behavior and Human Performance, 4(2), 142-175. https://doi.org/10.1016/0030-5073(69)90004-X

Aydin, S., Yaris, F., Dikici, M. F., \& Igde, F. A. (2015). Effect of rural practice observation on the anxiety of medical students, 102.

Belaid, L., Dagenais, C., Moha, M., \& Ridde, V. (2017). Understanding the factors affecting the attraction and retention of health professionals in rural and remote areas: A mixed-method study in Niger. Human Resources for Health, 15(1), 1-12. https://doi.org/10.1186/s12960-017-0227-y

Borracci, R. A., Arribalzaga, E. B., Couto, J. L., Dvorkin, M., Guerrero, R. A. A., Fernandez, C., \& Ferreira, L. N. (2015). Factors affecting willingness to practice medicine in underserved areas : a survey of Argentine medical students, $1-11$.

Brodribb, W., Zadoroznyj, M., \& Martin, B. (2016). How do rural placements affect urban-based Australian junior doctors' perceptions of working in a rural area? Australian Health Review, 40(6), 655-660. https://doi.org/10.1071/AH15127

Chuenkongkaew, W. L., Negandhi, H., Lumbiganon, P., Wang, W., Mahmud, K., \& Cuong, P. V. (2016). Attitude towards working in rural area and self-assessment of competencies in last year medical students: A survey of five countries in Asia. BMC Medical Education, 16(1), 1-9. https://doi.org/10.1186/s12909-0160719-9

Deressa, W., \& Azazh, A. (2012). Attitudes of undergraduate medical students of Addis Ababa University towards medical practice and migration, Ethiopia. BMC Medical Education, 12(1), 1. https://doi.org/10.1186/1472-6920-12-68

Deriba, B. K., Sinke, S. O., Ereso, B. M., \& Badacho, A. S. (2017a). Health professionals' job satisfaction and associated factors at public health centers in West Ethiopia. Human Resources for Health, 15(1), 1-8. https://doi.org/10.1186/s12960-017-0206-3

Deriba, B. K., Sinke, S. O., Ereso, B. M., \& Badacho, A. S. (2017b). Health professionals' job satisfaction and associated factors at public health centers in West Ethiopia. Human Resources for Health, 15(1), 1-7. https://doi.org/10.1186/s12960-017-0206-3

Geyman, J. P., Hart, L. G., Norris, T. E., Coombs, J. B., \& Lishner, D. M. (2000). Educating Generalist Physicians for Rural Practice: How Are We Doing? The Journal of Rural Health, 16(1), 56-80. https://doi.org/10.1111/j.1748-0361.2000.tb00436.x

Habeck, R., Hunt, A., Rachel, C. H., Kregel, J., \& Chan, F. (2010). Employee retention and integrated disability management practices as demand side factors. Journal of Occupational Rehabilitation, 20(4), 443-455. https://doi.org/10.1007/s10926-009-9225-9

Huicho, L., Molina, C., Diez-Canseco, F., Lema, C., Miranda, J. J., Huayanay-Espinoza, C. A., \& Lescano, A. G. (2015). Factors behind job preferences of Peruvian medical, nursing and midwifery students: A qualitative study focused on rural deployment. Human Resources for Health, 13(1), 1-12. https://doi.org/10.1186/s12960-015-0091-6

Jain, M., Gupta, S., Gupta, A., \& Roy, P. (2016). Attitude of would-be medical graduates toward rural health services: An assessment from Government Medical Colleges in Chhattisgarh. Journal of Family Medicine and Primary Care, 5(2), 440. https://doi.org/10.4103/2249-4863.192345 
Kizito, S., Baingana, R., Mugagga, K., Akera, P., \& Sewankambo, N. K. (2017). Influence of community-based education on undergraduate health professions students' decision to work in underserved areas in Uganda. BMC Research Notes, 10(1), 1-9. https://doi.org/10.1186/s13104-017-3064-0

Knevel, R. J. M., Gussy, M. G., Farmer, J., \& Karimi, L. (2015). Nepalese dental hygiene and dental students' career choice motivation and plans after graduation: A descriptive cross-sectional comparison. BMC Medical Education, 15(1), 1-9. https://doi.org/10.1186/s12909-015-0500-5

Lanktree, E., Cohen, M., Larocque, R., \& Omaswa, F. (2014). Special Issue: Addressing the human resources for health crisis through task-shifting and retention: results from the Africa Health Systems Initiative's research component. Special Issue: Addressing the Human Resources for Health Crisis through Task-Shifting and Retention: Results from the Africa Health Systems Initiative's Research Component., 12(Suppl. 1), I1-S8. Retrieved from http://www.human-resources-health.com/supplements/12/S1

Laven, G., \& Wilkinson, D. (2003). Rural doctors and rural back- grounds: How strong is the evidence? A systematic review. Australian Journal of Rural Health, 11, 277-284.

Martins, H., \& Proenca, T. (2012). Minnesota Satisfaction Questionnaire - psychometric properties and validation in a population of Portuguese hospital workers. Economics and Management, 471(October), 1-20.

McGrail, M. R., Russell, D. J., \& O'Sullivan, B. G. (2017). Family effects on the rurality of GP's work location: A longitudinal panel study. Human Resources for Health, 15(1), 8-10. https://doi.org/10.1186/s12960-0170250-Z

Myroniuk, L., Adamiak, P., Bajaj, S., \& Myhre, D. L. (2016). Recruitment and retention of physicians in rural Alberta: The spousal perspective. Rural and Remote Health, 16(1), 1-12.

Netemeyer, R. G., Bearden, W. O., \& Sharma, S. (2003). Scaling procedures : issues and applications. Thousand Oaks, Calif.: $\quad$ Sage $\quad$ Publications. $\quad$ Retrieved http://public.ebookcentral.proquest.com/choice/publicfullrecord.aspx?p=3032357

Paleologou, V., Kontodimopoulos, N., Stamouli, A., Aletras, V., \& Niakas, D. (2006). Developing and testing an instrument for identifying performance incentives in the Greek health care sector, 10, 1-10. https://doi.org/10.1186/1472-6963-6-118

Purohit, B., Maneskar, A., \& Saxena, D. (2016). Developing a tool to assess motivation among health service providers working with public health system in India. Human Resources for Health, 14(1). https://doi.org/10.1186/s12960-016-0111-1

Ramani, S., Rao, K. D., Ryan, M., Vujicic, M., \& Berman, P. (2013). For more than love or money: Attitudes of student and in-service health workers towards rural service in India. Human Resources for Health, 11(1). https://doi.org/10.1186/1478-4491-11-58

Ray, R. A., Young, L., \& Lindsay, D. B. (2015). The influences of background on beginning medical students' perceptions of rural medical practice. BMC Medical Education, 15(1), 1-9. https://doi.org/10.1186/s12909015-0339-9

Sapkota, B. P., \& Amatya, A. (2015). What factors influence the choice of urban or rural location for future practice of Nepalese medical students? A cross-sectional descriptive study. Human Resources for Health, 13(1), 1-9. https://doi.org/10.1186/s12960-015-0084-5

Schofield, D., Fletcher, S., Fuller, J., Birden, H., \& Page, S. (2009). Human Resources for Health Where do students in the health professions want to work ?, 8, 10-14. https://doi.org/10.1186/1478-4491-7-74

Shiratori, S., Agyekum, E. O., Shibanuma, A., Oduro, A., Okawa, S., Enuameh, Y., ... Kamiya, Y. (2016). Motivation and incentive preferences of community health officers in Ghana: An economic behavioral experiment approach. Human Resources for Health, 14(1). https://doi.org/10.1186/s12960-016-0148-1

Steidle, A., \& Gockel, C. (2013). Growth or security? Regulatory focus determines work priorities, 36(2), 173182. https://doi.org/10.1108/01409171311292261

Strasser, P. S. (2017). WHO Global Health Observatory Data. Retrieved from http://www.who.int/gho/en/

Syahmar, I., Putera, I., Istatik, Y., Furqon, M. A., \& Findyartini, A. (2015). Indonesian medical students' preferences associated with the intention toward rural practice. Rural and Remote Health, 15(4).

Taber, K. S. (2018). The Use of Cronbach's Alpha When Developing and Reporting Research Instruments in Science Education. Research in Science Education, 48(6), 1273-1296. https://doi.org/10.1007/s11165-0169602-2

Tolhurst, H., Bs, M. B., James, F., Mb, A. D., Fracgp, B. S., \& Fafphm, C. (2008). Factors affecting the career choices of family medicine graduates Recherche Intentions de pratique rurale, 54.

Young, L., Lindsay, D. B., \& Ray, R. A. (2016). What do beginning students, in a rurally focused medical course, think about rural practice? BMC Medical Education, 16(1), 1-7. https://doi.org/10.1186/s12909-0160829-4 